\title{
ASSOCIATION OF STRESS LEVEL WITH GENDER, SEMESTER OF STUDY AND CLINICAL PRACTICE IN UNDERGRADUATE PHYSICAL THERAPY STUDENTS: A CROSS SECTIONAL SURVEY
}

\author{
Hafiza Sana Ashraf, Maria Sohail, Fahad Tanveer, Aqsa Anjum, Haris Farooq, Haleema Masood* \\ University of Lahore, Lahore Pakistan, *University of Management and Technology, Lahore Pakistan
}

\begin{abstract}
Objective: To find association of stress level with gender, semester of study and clinical practice in undergraduate physical therapy students.

Study Design: Cross sectional observational survey.

Place and Duration of Study: Superior University, University of Management and Technology, University of Lahore, Lahore Medical and Dental College and Imperial University, from Apr to Jul 2019.

Methodology: Study was conducted on 358 students of physical therapy. Non-probability purposive sampling technique was used for data collection. Standard student Stress Inventory scale was used for the measurement of stress among students.

Results: Mean age of all the students in this study was $21.26 \pm 1.997$ with minimum of 18 years and with maximum of 25 years. There were $254(70.9 \%)$ female students and $104(29.1 \%)$ male students who participated in the study. Results showed 14.15\% "Mild Stress", 58.44\% "Moderate Stress" and 27.4\% "Severe Stress" in "Pre-Clinical Stage (1 $1^{\text {st }}$ - $4^{\text {th }}$ semester)". Chi-square test described a $p$-value of $<0.001$ (less than alpha level, $\alpha=0.05$ ) for gender, semester of study and clinical practice which showed a strong association among these variables and students' stress level.

Conclusion: Stress levels were more significant in females than males. "Severe Stress" was more prominent in ninth semester, "Moderate Stress" was more prevalent in third semester students and "Mild Stress" was highly present in sixth semester. Level of stress was more worthy of attention in "Pre-Clinical" students who were not doing any clinical practice.
\end{abstract}

Keywords: Clinical practice, Physical Therapy, Semester of study, Stress level, Undergraduate students.

This is an Open Access article distributed under the terms of the Creative Commons Attribution License (https://creativecommons.org/licenses/by-nc/4.0/), which permits unrestricted use, distribution, and reproduction in any medium, provided the original work is properly cited.

\section{INTRODUCTION}

Stress is defined as a set of psychological and physical responses to bad conditions or effects that degenerates physiology and disturbs psychological reactions happening with a threatening surroundings ${ }^{1}$. Stress is a serious psychological factor in our education system which have an effect on the academic efforts and student well-being ${ }^{2}$. The prevalence of stress among private medical university students was determine as $60 \%$ in Pakistan, $19 \%$ in USA, $49.1 \%$ in India ${ }^{3}$. Doctor of physical therapy (DPT) is a new immerging field related to health with more and more complex technologies and practices.

To become expert in the field of physio-therapy there is a huge amount of pressure and stress on the students to cope with upcoming new techniques to treat the patients efficiently ${ }^{4}$. Most of the times Physiotherapy students experienced higher levels of stress than their age and gender matched peers, which can badly affect their academic performance and wellbeing. That's why, finding methods in managing stress is important for the student's wellbeing and academic success 5 . Out of $71 \%$ of undergraduate physiotherapy

Correspondence: Dr Hafiza Sana Ashraf, University Institute of Physical Therapy, University of Lahore, Lahore Pakistan

Received: 04 Dec 2020; revised received: 22 Feb 2021; accepted: 23 Feb 2021 students feel that their course is more difficult than expected. A study conducted in Ireland on undergraduate physical therapy students concluded that $27 \%$ students exhibited probable psychological morbidity, which is much greater than the general population ${ }^{6}$. Source of academic stress in physical therapy education system was also investigated by previous studies.

One of the studies concluded that the medical students studying in Pakistan suffered from difficulties in concentration and anxious behavior and low moods which were the signs of stress due to examination system. In Western countries depression and stress in Michigan University students are reported to be associated with Low Grade Point Average (GPA) ${ }^{7}$. Other studies conducted on medical students have found that stress was associated with depression and anxiety, sleeping problems interpersonal conflicts and lower academic and clinical performance.

In a study moderate level of stress was found in the nursing students. High workload and assignments given for homework were the most common stressors were found in the study ${ }^{8}$.

Students who have stress were found to be less attentive, have low concentration, have bad decision making and their interaction with patients was not efficient. Stress was also found to be associated with 
drug abuse, use of alcohol and suicides in medical students ${ }^{9}$. Stress has an adverse effect on professional education because it has the potential to disturb human physiology that includes the capacity to absorb the information. High levels of stress in health care students may lead to impaired academic performance, to doubt there abilities, lack of empathy when working with patients ${ }^{10}$. Physiotherapy is a healthcare profession, and society has lots of expectations from these caregivers. If healthcare professionals are stressed out, how can they provide healthcare services to their patients. In this regard, if stress affects them in their student life, they would become patients before becoming healthcare providers. Therefore, the purpose of this study was to evaluate students' experience of stress during their medical education period its association with gender, the semester of study, \& clinical practice. Identification of this association would help the students to take preventive measures to cope up with the stress. The purpose of this study was to find association of stress level with gender, semester of study and clinical practice in undergraduate physical therapy students.

\section{METHODOLOGY}

A cross-sectional study was conducted on 358 students of physical therapy. Data were collected from Superior University, University of Management and Technology, University of Lahore, Lahore Medical and Dental College and Imperial University after obtaining informed consent. The duration of study was 4 months from April to September 2019. Written permission and ethical approval were taken from the University Institutional Review Board, The University of Lahore (IRBUOL-FAHS/719-I/2020). Non-probability convenient sampling technique was used for data collection. Student stress inventory (SSI) (validity $0.805 \%)^{11}$, was used for measuring stress among students.

Concerning scoring, the SSI was planned with ordinal scale and the worth imprint given for every options are 1 for "Never", 2 for "Somewhat Frequent", 3 for "Frequent" and 4 for "Always". The 40 items are appraised on a 4 Point Likert scale. As far as score investigation and analysis, SSI proposed the individuals who acquired the score within 122-160 reflects having the severe stress, $81-121$ reflects having the moderate stress and the individuals who got score 40-80 reflects having mild stress ${ }^{11}$. Students from all semesters, both genders, age ranging between $18-25$ years ${ }^{12}$, were included whereas all those students with depression or anxiety, schizophrenia and attention deficit hyperactivity disorder were excluded for this study.
After taking informed written consent data were collected from Student Stress Inventory questionnaire. The data were analyzed using SPSS-21. For Age, mean and standard deviation were calculated whereas frequencies and percentages were calculated for gender, semester of study and clinical practice. To calculate association of stress level with gender, semester of study and clinical practice, chi-square test was used.

\section{RESULTS}

Mean age of all the students in this study was $21.26 \pm 1.997$ years with maximum of 25 years and minimum of 18 years (table-I). There were $70.9 \%$ female students and $29.1 \%$ male students who participated in the study. Among the students who have participated, there were $13.4 \%$ students from "First Semester", $8.4 \%$ from "Second Semester", 16.8\% from "Third Semester", 16.2\% from "Fourth Semester", 4.2\% from "Fifth Semester", 11.2\% from "Sixth Semester", 7.0\% from "Seventh Semester", 8.9\% from "Eighth Semester", 3.6\% from "Ninth Semester" and 10.3\% students from "Tenth Semester". Among all the respondents, $61.2 \%$ were from "Pre-Clinical Stage ( $1^{\text {st }} 4^{\text {th }}$ Semester)" in which they were not going to hospital neither for clinical rotations nor for internships, 20.9\% were going for "Clinical Rotations in Teaching Hospital $\left(5^{\text {th }}-10^{\text {th }}\right.$ Semester) and $17.9 \%$ were also doing "Internships in other hospital settings $\left(1^{\text {st }}-10^{\text {th }}\right.$ Semester$) ~ a p a r t ~ f r o m$ Clinical Rotations (table-II).

Table-I: Descriptive statistics of age $(n=358)$.

\begin{tabular}{l|c|c|c}
\hline Variable & Mean & Standard Deviation & Range \\
\hline Age (Years) & 21 & 2 & $(18-25)$ \\
\hline
\end{tabular}

Table-II: Descriptive statistics of gender, semester of study and clinical practice $(n=358)$.

\begin{tabular}{|c|c|c|}
\hline Variable & Construct & n (\%) \\
\hline \multirow{2}{*}{ Gender } & Male & $104(29.1)$ \\
\hline & Female & $254(71)$ \\
\hline \multirow{10}{*}{$\begin{array}{l}\text { Semester of } \\
\text { study }\end{array}$} & 1st Semester & $48(13.4)$ \\
\hline & 2nd Semester & $30(8.4)$ \\
\hline & 3rd Semester & $60(16.8)$ \\
\hline & 4th Semester & $58(16.2)$ \\
\hline & 5th Semester & $15(4.2)$ \\
\hline & 6th Semester & $40(11.2)$ \\
\hline & 7th Semester & $25(7)$ \\
\hline & 8th Semester & $32(8.9)$ \\
\hline & 9th Semester & $13(3.6)$ \\
\hline & 10th Semester & $37(10.3)$ \\
\hline \multirow{3}{*}{$\begin{array}{l}\text { Clinical } \\
\text { Practice }\end{array}$} & Pre-Clinical & $219(61.2)$ \\
\hline & Clinical Rotations & $75(20.9)$ \\
\hline & Internships & $64(17.9)$ \\
\hline
\end{tabular}

There were $15.7 \%$ females and $28.8 \%$ males with "Mild Stress (40-80)", 50\% females and 56.7\% males 
with "Moderate Stress (81-121)", 34.2\% females and $14.4 \%$ males with "Severe Stress (122-160)". Chi square test showed a $p$-value of $<0.001$ that is less than alpha level $(a=0.05)$. It means there was a strong association between gender and stress. "Mild stress" was most cal practice. Student stress inventory scale was used for data collection. In this study strong association was found between levels of stress with gender ( $p$-value $<0.001)$. Female students were found to be more stressed in the study which goes with the literature as

Table-III: Association of stress level with gender, semester of study and clinical practice (n=358).

\begin{tabular}{|c|c|c|c|c|c|}
\hline \multicolumn{6}{|c|}{ Level of Stress } \\
\hline Variables & Construct & Mild & Moderate & Severe & $p$-value \\
\hline \multirow{2}{*}{ Gender } & Male & $30(28.8 \%)$ & $59(56.7 \%)$ & $15(14.4 \%)$ & \multirow{2}{*}{$<0.001$} \\
\hline & Female & $40(15.7 \%)$ & $127(50 \%)$ & $87(34.2 \%)$ & \\
\hline \multirow{10}{*}{$\begin{array}{l}\text { Semester of } \\
\text { Study }\end{array}$} & 1st Semester & $15(31.25 \%)$ & $19(\% 39.58)$ & $14(29.1 \%)$ & \multirow{10}{*}{$<0.001$} \\
\hline & 2nd Semester & $4(13.33 \%)$ & $16(53.33 \%)$ & $10(33.33 \%)$ & \\
\hline & 3rd Semester & $6(10 \%)$ & $45(75 \%)$ & $9(15 \%)$ & \\
\hline & 4th Semester & $7(12.06 \%)$ & $35(60.34 \%)$ & $16(27.58 \%)$ & \\
\hline & 5th Semester & $1(6.66 \%)$ & $5(33.33 \%)$ & $9(60 \%)$ & \\
\hline & 6th Semester & $20(50 \%)$ & $12(30 \%)$ & $8(20 \%)$ & \\
\hline & 7th Semester & $5(20 \%)$ & $13(52 \%)$ & $7(28 \%)$ & \\
\hline & 8th Semester & $9(28.1 \%)$ & $12(37.5 \%)$ & $11(34.37 \%)$ & \\
\hline & 9th Semester & - & $5(38.46 \%)$ & $8(61.53 \%)$ & \\
\hline & 10th Semester & $3(8.11 \%)$ & $24(64.86 \%)$ & $10(27.03 \%)$ & \\
\hline \multirow{3}{*}{$\begin{array}{l}\text { Clinical } \\
\text { Practice }\end{array}$} & Pre-Clinical & $31(14.15 \%)$ & $128(58.44 \%)$ & $60(27.4 \%)$ & \multirow{3}{*}{$<0.001$} \\
\hline & Clinical Rotations & $13(17.33 \%)$ & $32(42.66 \%)$ & $30(40 \%)$ & \\
\hline & Internships & $26(40.625 \%)$ & $26(40.625 \%)$ & $12(18.75 \%)$ & \\
\hline
\end{tabular}

$(50 \%)$ in sixth semester and least $(0 \%)$ in ninth semester. "Moderate stress" was most (75\%) in third semester and least (33.33\%) in fifth semester. "Severe stress" was much more $(61.53 \%)$ in students of ninth semester and least $(15 \%)$ in students of third semester. Chisquare test showed $p$-value of $<0.001$ that is less than alpha level $(\alpha=0.05)$. It means there was a strong association between semester of study and students' level of stress. Results showed 14.15\% "Mild Stress", 58.44\% "Moderate Stress", 27.4\% "Severe Stress" in "Pre-Clinical Stage (1 $1^{\text {st }} 4^{\text {th }}$ Semester)"; $17.33 \%$ "Mild Stress", 42.66\% "Moderate Stress", 40\% "Severe Stress" in "Clinical Rotations (5th-10th Semester)" and 40.63\% "Mild Stress", 40.63\% "Moderate Stress", 18.75\% "Severe Stress" in "Internship Stage ( $1^{\text {st }}-10^{\text {th }}$ Semester)".

Results showed severe, moderate and mild levels of stresses most in students with "Pre-Clinical Stage ( $1^{\text {st }} 4^{\text {th }}$ Semester $)$ " and least in those students who were doing both "Internships in other Hospital settings as well as clinical rotations in Teaching Hospital $\left(1^{\text {st }}-10^{\text {th }}\right.$ Semesters)". Chi-Square test described a $p$-value of $<0.001$ that is less than alpha level $(\alpha=0.05)$. It means there was a strong association between Clinical Stage and Students' level of Stress (table-II).

\section{DISCUSSION}

The current study is conducted on undergraduate students of physiotherapy to find association between level of stress with gender, semester of study and clini- female students become more anxious and depressed than men ${ }^{6,13}$. A strong association was found between level of stress and clinical practice with a $p$-value $<0.001$ in this study. The study reveals that students who are not involved in any clinical practice or trainings are more stressful than the students who are doing clinical work. Just like the current study another study conducted by Maher et al showed the same results as students from clinical medical years were found to be less stressed and anxious than the students who are not involved in clinical practice which could be due to maturation of students ${ }^{14}$.

In contrast to current study another study conducted by Verma et al reveals that more stress was found in transition from preclinical to clinical stage as clinical stage increases workload on students ${ }^{15}$. Similar to the above study another study conducted by Dutta et al showed that final year medical students were more stressed than the students of $1^{\text {st }}$ and $2^{\text {nd }}$ year ${ }^{16}$. In this study a strong association was found between levels of stress with semester of study with $p$-value $<0.001$. This study reveals that students from $9^{\text {th }}$ semester are more stressful than any other semester. In contrast to the current study another study conducted by Shah et al reveals that students from $3^{\text {rd }}$ year (Semester $5^{\text {th }}$ and $6^{\text {th }}$ ) were more stressful ${ }^{17}$.

In many studies it was found that higher expectations from parents, difficult academic course, higher workload, assignments given for home, frequent exam- 
inations, anxiety were the common stressors. A study conducted by Alsalhi et al suggested that to cope of with these stressors, there is a need of proper counseling for students. Preventive measures should be taken by the teaching institutes and mental health services should be provided to the students ${ }^{18}$.

\section{Declarations}

Before collecting data, purpose of study was briefed out to the undergraduate students and with their voluntary approval, data were taken. Ethics approval was also taken from the University Institutional Review Board, The University of Lahore.

\section{ACKNOWLEDGEMENT}

Authors might want to thank all the university students of Physical Therapy Department, management and Department Heads of all institutions whose approval and involvement has gone into the attainment of this research.

\section{CONCLUSION}

Stress levels were more significant in females than males. "Severe Stress" was more prominent in ninth semester, "Moderate Stress" was more prevalent in $3^{\text {rd }}$ semester students and "Mild Stress" was highly present in sixth semester. Level of stress was more worthy of attention in "Pre-Clinical" students who were not doing any clinical practice. Further extensive investigations using different research explorations among PT students' sample of sufficient size may help escalate our conception of the source of certain stressors. The more significant level of stress requires the need of the universities to build up advantageous counseling, illuminative facilities and psychological help to exceed their performance in studies, to improve the quality of life for students of medical profession.

\section{CONFLICT OF INTEREST}

This study has no conflict of interest to be declared by any author.

\section{REFERENCES}

1. Alanazi A, Alotaibi D, Alabadli A, Alalaty H, Alanzi AM, Qureshi S. Effects of Stress on Students in College of Applied Medical Sciences. J Med Ethics 2014; 4(3): 255-61.

2. Liu CH, Stevens $\mathrm{C}$, Wong $\mathrm{SH}$, Yasui $\mathrm{M}$, Chen JA. The prevalence and predictors of mental health diagnoses and suicide among US college students: Implications for addressing disparities in service use. Depress Anxiety 2019; 36(1): 8-17.
3. Saravanan C, Wilks R. Medical students' experience of and reaction to stress: the role of depression and anxiety. Sci World J 2014; 2014(1): 1-2.

4. Afridi A, Fahim MF. Identification of stressors and perceptional difference of stress in first and final year doctor of physical therapy students; a comparative study. J Pak Med Assoc 2019; 69(4): 572-75.

5. Chambers J, Phillips B, Burr M, Xiao D. Effects of meditation on stress levels of physical therapist students. J Phys Educ Sport 2016; 30(3): 33-39.

6. Siddiqi FA, Azim ME, Babur MN, Osama M, Waheed A, Memon AR. Psychological stress and satisfaction with life among physical therapy students of Rawalpindi/Islamabad, Pakistan. J Pak Med Assoc 2019; 69(7): 973-75.

7. Alanazi A, Alotaibi D, Alabadli A, Alalaty H, Alanzi AM, Qureshi S. Effects of stress on students in College of Applied Medical Sciences. J Res Med Educat Ethics 2014; 4(3): 255-61.

8. Labrague LJ. Stress, stressors, and stress responses of student nurses in a government nursing school. Health Sci J 2014; 1(2): 46-48.

9. Yusoff MSB, Rahim AFA. Stress, stressors and coping strategies: first year medical students in Malaysian public universities. 1 ed: VDM Publishing Saarbrücken 2011; 1(2): 45-50.

10. Jacob T, Einstein O. Stress among bachelor physical therapy students in Israel during clinical practice and its association with academic achievements-Results of a longitudinal study. Inter J Allied Health Sci Pract 2016; 14(1): 1-9.

11. Arip M, Kamaruzaman D, Roslan A, Ahmad A, Rahman M, Malim T. Development, validity and reliability of student stress inventory (SSI). Soc Sci 2015; 10(7): 1631-38.

12. Harada T, Kobayashi R, Wada K, Nishihara R, Kondo A, Akimitsu $\mathrm{O}$, et al. Effect of birth season on circadian typology appearing in Japanese young children aged 2 to 12 years disappears in older students aged 18 to 25 years. Chronobiol Int 2011; 28(7): 638-42.

13. Sabih F, Siddiqui FR, Baber MN. Assessment of stress among physiotherapy students at Riphah Centre of Rehabilitation Sciences. J Pak Med Assoc 2013; 63(3): 346-49.

14. Fuad MD, Al-Zurfi BMN, Abdelqader MA, Bakar MFA, Elnajeh M, Abdullah MR. Prevalence and risk factors of stress, anxiety and depression among medical students of a private medical university in Malaysia. Med Educ 2015; 7(2): 1-5.

15. Verma S, Nambiar VK. Prevalence of stress among undergraduate physiotherapy students. National Editorial Advisory Board 2014; 8(4): 4295-98.

16. Anuradha R, Dutta R, Raja JD, Sivaprakasam P, Patil AB. Stress and stressors among medical undergraduate students: A crosssectional study in a private medical college in Tamil Nadu. Indian J Community Health 2017; 42(4): 222-25.

17. Shah T, Patel MD, Shah H. A study to evaluate depression, anxiety and stress among undergraduate physiotherapy students - an institution based pilot study. Int J Curr Res Rev 2016; 8(20): 20-24.

18. Alsalhi AH, Almigbal TH, Alsalhi HH, Batais MA. The relationship between stress and academic achievement of medical students in King Saud University: A cross-sectional study. Kuwait Med J 2018; 50(1): 60-65. 